\title{
SOBRE A COLONIALIDADE DA LINGUAGEM ${ }^{1}$
}

\author{
About the coloniality of language
}

\author{
Gabriela VERONELLI \\ Binghamton University \\ gverone0@binghamton.edu \\ Tradução de Silvana DAITCH \\ Universidade Federal do Paraná \\ silvanadaitch@hotmail.com \\ https://orcid.org/0000-0002-8578-8487
}

RESUMO: Este artigo apresenta um novo marco teórico para analisar relações linguísticas de poder e examina os efeitos linguísticos do que Aníbal Quijano chamou de a colonialidade do poder. A colonialidade da linguagem refere-se a um processo de racialização de populações colonizadas como agentes comunicativos (ou seja, possíveis interlocutores), que começa com a Conquista da América e que continua até hoje. A pesquisa foi focada na desumanização das populações colonizadas e escravizadas, e o concomitante desprezo das suas linguagens e maneiras sociais de dar sentido, interpretadas como expressões de "natureza" inferior. Os resultados são uma contribuição original ao debate sobre a relação histórica entre colonialismo, raça, etnicidade e linguagem na América. $\mathrm{O}$ argumento levantado sugere que há conexão entre a redução das populações colonizadas e racializadas a um status de seres não-humanos, e uma ideologia linguística analisada como monolinguajar, que esconde a opressão colonial dialógica e discursivamente. PALAVRAS-CHAVE: Colonialidade; Comunicação; Comunicação simples; Linguagem; Modernidade; Monolinguajar; Raça; Racialização.

ABSTRACT: This paper presents a new theoretical framework for analyzing linguistic power relations and it examines the linguistic effects of what Anibal Quijano has called coloniality of power. The coloniality of language refers to a process of racialization of colonized people as communicating agents (ie, as potential interlocutors) that begins with the conquest of America and nowadays. The rese-

${ }^{1}$ Publicação original: VERONELLI, G. A. Sobre la colonialidad del lenguaje. Universitas Humanística, v. 81, 2015, p. 33-58.

A elaboração deste artigo foi possível graças ao apoio da Ross Fund Fellowship e a Graduate School Fellowship da Binghamton University, State University of New York, E.U.A. É um artigo de reflexão que presenta uma perspectiva crítica sobre a relação entre raça, linguagem, colonização e geopolíticas de conhecimento na América. 
arch focuses on the dehumanization of the colonized and enslaved populations, and the concomitant contempt of their languages and social ways of making sense, interpreted as expressions of his inferior 'nature'. The results are an original contribution to the debate on the historical relationship between colonialism, race, ethnicity, and language in America. The argument suggests that there is a connection between the reduction of the colonized and racialized populations to a status of non-humans, as well as a monolingual linguistic ideology that hides colonial oppression dialogically and discursively. KEYWORDS: Colonialism; Communication; Language; Modernity; Monolingual; Race; Racialization; Simple communication.

\section{INTRODUÇÃO}

$\mathrm{O}$ diálogo como projeto e método de resistência à unilateralidade e unidimensionalidade discursivas do eurocentrismo é central em vários autores que trabalham formas de resistência à colonização. Por exemplo, a pedagogia dialógica de Paulo Freire (1998), a transmodernidade de Enrique Dussel (1992) ou a interculturalidad de Catherine Walsh (2009). Este artigo discute que o diálogo não é suficiente para pôr em prática o projeto incompleto e inconcluso da descolonização, porque o próprio diálogo foi colonizado. Partindo da pergunta sobre os efeitos da colonialidade na linguagem e na comunicação, desenvolve-se o conceito de colonialidade da linguagem como forma de entender esse processo, que começa na conquista da América e continua até a atualidade.

A primeira sessão "O que é colonialidade?" faz uma revisão da teoria da colonialidade do poder de Aníbal Quijano e a sua forma de entender a convergência entre a colonização da América, o desenvolvimento do capitalismo eurocêntrico como padrão mundial de poder e a imposição de um sistema de classificação social vertical da população baseado na ideia de raça. Entendida como "referência a supostas estruturas biológicas diferenciais entre colonizadores e colonizados" (QUIJANO, 2014, p. 777), a ideia moderna de raça verticaliza a população em níveis de humanidade. Dessa maneira, segundo Quijano, a lógica racial (quanto mais "branco" mais humano, e vice-versa) rearticula a relação histórica vencedores-vencidos e naturaliza as relações coloniais de dominação além dos limites da administração colonial. Por sua vez, esse sistema de classificação racial estrutura cada um dos projetos, âmbitos e dimensões (materiais e intersubjetivas) da existência social cotidiana e a escala social mundial. Desta forma, e segundo Quijano, a lógica racial não compreende somente características físicas, mas também estende-se aos campos interpessoais e intersubjetivos da atividade humana, como a linguagem, o conhecimento, a geografia e a religião. 
A sessão "O que é linguagem?” inclui uma descrição do paradigma da linguagem desenvolvido nos tempos da Conquista. Argumenta-se que esse paradigma traz consigo a lógica da colonialidade, pois, prescreve uma relação entre linguagem e poder; linguagem e território; linguagem e escrita; linguagem e religião; e linguagem e civilidade, que define os sujeitos colonizados como seres sem linguagem no sentido humano íntegro (o que mais tarde se denominará comunicadores simples) e tende a interpretar os meios de expressividade que eles têm como falhos e rudimentares (o que a autora chama de comunicação simples).

A terceira sessão “O que é colonialidade da linguagem?” argumenta que existe um vínculo entre, por um lado, a desumanização das populações racializadas e o concomitante desprezo das suas linguagens como simples expressão de sua 'natureza' inferior, e por outro, uma ideologia linguística - entendida como monolinguajar - que oculta a opressão colonial, dialógica e discursivamente. A hipótese que se propõe é que a colonialidade da linguagem bloqueia a comunicação dialógica racional entre colonizadores e colonizados ao negar aos segundos a capacidade e a agência comunicativa dos primeiros.

\section{O QUE É COLONIALIDADE?}

Esta pesquisa está vinculada e pretende contribuir com o projeto coletivo de pesquisa conhecido como giro decolonial (MALDONADO-TORRES, 2005). Nas últimas três décadas, o giro decolonial fez uma intervenção crítica para repensar a raça e a formação de subjetividades raciais a nível mundial, como ponto de partida para uma crítica aos fracassos da modernidade eurocêntrica. O giro decolonial é formado por uma rede de pesquisadores(as) latino-americanos(as), caribenhos(as) e latinos(as) dos EUA², e apresenta-

\footnotetext{
${ }^{2}$ Esta é uma apresentação bastante esquemática do projeto coletivo MCD. No geral, a rede está associada ao trabalho de três figuras centrais: o filósofo argentino-mexicano Enrique Dussel, o sociólogo peruano Aníbal Quijano e o semiólogo e teórico cultural argentino-estadunidense Walter Mignolo. Há, porém, um número crescente de pesquisadores-pensadores-ativistas associados ao grupo: Edgardo Lander na Venezuela; Santiago Castro-Gómez na Colômbia; Catherine Walsh no Equador; Zulma Palermo na Argentina; Jorge Sanjinés na Bolívia; Oscar Guardiola na Inglaterra; María Lugones, Freya Schiwy, Fernando Coronil, Ramón Grosfógel, Jorge Saldívar, Ana Margarita Cervantes-Rodríguez, Nelson Maldonado-Torres e Arturo Escobar nos Estados Unidos. Junto-me a esta nova geração de pesquisadores decoloniais, estudantes de pós-graduação e flamantes doutores de várias universidades latino-americanas e estadunidenses. Não é possível expor aqui uma lista completa da bibliografia produzida nas últimas três décadas, porém, alguns dos volumes coletivos produzidos pelo grupo incluem: Castro-Gómez e Mendieta (1998); Castro-Gómez (2000); Mignolo (2000; 2007); Walsh; Schiwye Castro-Gómez (2002); e Isasi-Díaz e Mendieta (2011). Para uma genealogia do coletivo, suas principais ideias e projetos, o artigo Worlds and Knowledges Otherwise: The Latin American modernity/coloniality Research Program, de Arturo Escobar (2004), é um bom lugar por onde começar, tal como as páginas web dos membros e os projetos da pesquisa associados ao coletivo. 
se como um espaço para o desenvolvimento de teorias críticas que não se encaixam numa história linear de paradigmas modernos. O giro decolonial procura desenvolver uma perspectiva geopolítica do conhecimento a partir de um tempo/espaço específicos, através de um lócus de enunciação que não é o de um autor ou autora particular, mas sim de outro historicamente marginalizado e ignorado.

O giro decolonial movimenta-se em duas direções simultaneamente. Uma delas é analítica: articulada em torno à noção de colonialidade do poder, descrevendo o legado vivo do colonialismo espanhol e português do século XVI nas sociedades contemporâneas, sob a forma de uma organização racializada da sociedade que sobreviveu ao colonialismo formal e foi integrada às sucessivas ordens sociais. A outra direção é programática e articula-se em torno à noção de decolonialidade. O propósito global, horizontal e de longa duração que se pretende alcançar é decolonizar ${ }^{3}$ todas as áreas da matriz colonial do poder para liberar a plenitude das relações humanas (MIGNOLO, 2013). Dito de outra forma, o giro decolonial não pretende negar as contribuições que a modernidade eurocêntrica trouxe à história da humanidade, mas sim abrir espaço para perspectivas epistêmicas e experiências de vida outras ${ }^{4}$ que emanam de uma multiplicidade de subjetividades que a relação modernidade/colonialidade ignorou, deslocou e subalternizou intencionalmente a nível global.

O principal propósito deste artigo é mover-se na direção analítica e levantar algumas das perguntas teoricamente necessárias acerca das implicações da presença da colonialidade na relação entre linguagem, comunicação e poder.

Os pensadores-ativistas do giro decolonial historiam a raça, ao invés de pensála como conceito, experiência ou fenômeno. Eles periodizam essa história começando no século XVI. Tal periodização focaliza na conjuntura da colonização da América,

\footnotetext{
${ }^{3}$ Como enfatiza Catherine Walsh (2009), "dizer decolonial, suprimindo o "s", não é promover o anglicismo, mas marcar a diferença com o "des" que remete no castelhano. Pois não se trata de um desfazer ou reverter o colonial e passar de um momento colonial para um não-colonial, como se as suas marcas deixassem magicamente de existir; trata-se, porém, de um posicionamento, uma atitude para pensar, viver, fazer, que visibilize e fortaleça os lugares de exterioridade e as construções alternativas" (DUSSEL, 1992, p. 15).

${ }^{4}$ Quando falo de "experiências de vida outras" estou me apropriando do vocabulário e da gramática do giro decolonial (em particular, de Catherine Walsh, 2009), no qual dizer "outras experiências de vida" não é o mesmo que "experiências de vida outras". A diferença está nos pontos de partida. Enquanto a busca por "outras experiências de vida" (ou, no caso, "outras lógicas", "outras alternativas", "outras formas", "outras ideias", "outros modelos" etc.) presumem a centralidade e universalidade da modernidade eurocêntrica, o interesse por "experiência de vida outras" enfatiza algo 'além' dessa modernidade eurocêntrica e seu projeto civilizatório ocidental. Ou seja, as experiências, práticas e perspectivas ancoradas às lutas pela vida que, desde o século XVI e até hoje não deixaram de existir.
} 
tendo a origem do sistema-mundo capitalista (WALLERSTEIN, 1974) como o momento inaugural da racialização como inferioridade natural. Um termo fundamental nessa periodização é a colonialidade do poder, introduzido por Quijano (1989) para teorizar o capitalismo global-autocentrado.

Em "Colonialidade do poder e classificação social”, Quijano explica que o padrão de poder capitalista global-autocentrado se articula em dois eixos: colonialidade e modernidade (2007, p. 286). Esses eixos organizam o sentido e as formas de controle e dominação em cada espaço da experiência social. ${ }^{5}$ A colonialidade introduz uma classificação básica e universal da população mundial em termos de raça. A invenção da raça é tida como nodal e fundamental porque transforma as relações de superioridade e inferioridade - previamente entendidas como produto da guerra, dominação e poder - em fenômenos a-históricos e naturais. Quijano argumenta que a introdução dessa classificação racial reorganizou todas as relações sociais na sociedade colonial, criando novas identidades sociais e geoculturais e redefinindo outras ${ }^{6}$. Essas identidades raciais eram, por sua vez, constitutivas das múltiplas hierarquias coloniais no século XVI. As empresas coloniais/imperiais dos séculos seguintes (Holanda século XVII; França e Inglaterra século XVIII; EUA século XX) expandiram tal classificação racial a toda a população do planeta (QUIJANO, 2014).

Nesse sentido, a colonialidade não se refere somente à classificação racial, mas a um fenômeno integral e global que permeia todos e cada um dos aspectos e situações da existência social, enquanto a distribuição das hierarquias, lugares e papéis sociais é racializada e geograficamente diferenciada. Por exemplo, no contexto econômico, a mão de obra forçada ou barata é provida por populações não-europeias/não-brancas periféricas, enquanto a relação capital-trabalho assalariado se concentra nos países do centro (incluindo

\footnotetext{
${ }^{5}$ Os quatro espaços (ou esferas) interconectados da existência social, que são objeto das lutas (capitalistas) de poder são: o econômico (apropriação da terra e seus recursos, e exploração do trabalho), o controle da autoridade (estabelecendo diferentes formas de sistemas governamentais, jurídicos, financeiros, e militares), o público (impondo uma normativa sexual e naturalizando os papéis de gênero através da institucionalização da família nuclear) e o intersubjetivo (controle da cultura, da subjetividade e especialmente do conhecimento através da colonização e da educação) (QUIJANO, 2014, p. 792-793).

6 "Termos como espanhol e português, e muito mais tarde europeu, que até então indicavam apenas uma origem geográfica ou um país de origem, adquiriram desde então uma conotação racial em referência às novas identidades [...] Em trezentos anos, o grande número de gentes que povoavam os territórios conquistados (cada uma com a sua história, linguagem, cultura, memória e identidade próprias) foram homogeneizadas em uma única identidade: índios. Essa nova identidade era racial, colonial e negativa. $\mathrm{O}$ mesmo aconteceu com as populações que foram tiradas à força de suas terras nativas e comunidades na África para se tornarem escravos na América. No espaço de trezentos anos, todos eram negros" (QUIJANO, [2000] 2014, p. 778; 801). Revista X, v. 16, n. 1, p. 80-100, 2021. 
o centro da periferia) e entre europeus/brancos (GROSFÓGUEL, 2009, p. 20). Nesse exemplo, a colonialidade do trabalho se evidencia como uma articulação fundamental entre racialização e exploração, com vistas à geração de lucros e à acumulação de capital.

A modernidade é o outro eixo do capitalismo global eurocêntrico e refere-se a um universo específico de relações intersubjetivas de dominação segundo a hegemonia de instituições europeias/brancas. Para caracterizar a modernidade, Quijano se concentra na produção de um tipo de conhecimento adequado às necessidades do capitalismo. Desta forma, a externalização do objeto de conhecimento (objetivação) e a ênfase na quantificação são características peculiares da perspectiva cognitiva da modernidade, ou eurocentrismo ${ }^{7}$, à medida que adaptam o conhecimento ao capitalismo (tudo pode ser medido e equiparável em prol do intercâmbio). Portanto, quando Quijano pensa no poder social e no capitalismo o faz em termos de colonialidade e modernidade, em termos da racialização, da objetivação e quantificação do trabalho, e também em termos de intersubjetividade. A inextricável relação entre os dois eixos - colonialidade e modernidade - naturaliza as experiências das gentes $^{8}$ dentro desse modelo de poder (QUIJANO, [2007] 2014).

A noção de naturalização é muito útil, porque coloca em evidência que existe um fazer, um processo de produção e construção de um entendimento intersubjetivo da experiência da colonialidade. Dizer que algo é 'natural' é sugerir que é produzido, e que parte dessa produção foi feita por um quadro cognitivo que esconde a si mesmo e representa sua aparência como dada, como não-feita, não-artificial. $O$ crucial é que a produção se elabora desde dentro da inter-relação entre os dois eixos de poder. A propósito, o tandem 'modernidade/colonialidade' (ESCOBAR, 2004) é usado pelos pensadores-ativistas decoloniais para significar esta inter-relação, tanto sua inseparabilidade - a colonialidade é constitutiva da modernidade e não existe modernidade sem colonialidade - como sua dupla face, a modernidade é o lado iluminado e visível da história do capitalismo globalautocentrado, e a colonialidade é seu lado escuro, escondido e invisibilizado: "Assim, para escavar a colonialidade é imprescindível se referir ao projeto da modernidade, não o contrário, pois a colonialidade aponta às ausências que se produzem nos relatos da modernidade" (MIGNOLO, 2007, p. 17).

\footnotetext{
7 "O eurocentrismo - é importante destacar - não se trata da perspectiva de conhecimento da gente da Europa, mas do mundo autocentrado; de todos aqueles que são educados sob a hegemonia do capitalismo global" (QUIJANO, [2007] 2014, p. 287).

${ }^{8}$ Termo que se usa na literatura decolonial latino-americana. Tem o sentido de enfatizar as diferentes formas de viver, pensar e ser de cada grupo. O uso do plural "gentes" marca ainda mais essa diferença cultural-epistêmica-ontológica e a multiplicidade de diferentes. O projeto político-intelectual decolonial impulsiona a necessidade de mudar os termos tanto na conversação como no conteúdo. 
Podemos pensar a articulação modernidade/colonialidade como um paradigma, um marco constitutivo da percepção do "colonizador-colonializador" (NOBOA, 2005) e da estrutura de poder que permite que essa percepção funcione ao ler e navegar na realidade. Entender as populações "colonizadas-colonializadas" como não-humanos ou menos que humanos constitui o conteúdo deste paradigma. Porém ao denominá-lo assim, paradigma, estamos reconhecendo-o como tal: uma poderosa construção do real que foi imposta sobre as gentes que se tornaram "colonizados-colonializados". Quanto à teorização da raça - e isso é crucial para a minha abordagem sobre a relação entre raça, linguagem e comunicação - o enfoque histórico decolonial marca uma diferença (e ao mesmo tempo uma relação de complementação) entre raça como categoria de classificação das populações mundiais e racialização como processo de desumanização de longa duração.

A raça é uma construção mental que prescreve uma desigualdade natural entre populações e sociedades, ao transformar diferenças em valores e atribuir valor a certas populações e sociedades enquanto tira e marginaliza outras. Nesse sentido, a raça é uma ficção. A classificação racial não é um fato histórico, mas sim um a priori. Passa pela história, sim, mas não pertence aos bastidores da história. A racialização é o processo de longa duração que transforma essa ficção em realidade. É o processo de configuração estrutural da classificação racial através de instituições, leis, formas de tratamento, práticas e desejos que distribuem a população mundial nas categorias, lugares e papéis da estrutura de poder, colocando todos aqueles que têm sido desvalorizados em situações e relações como seres naturalmente inferiores (em contraste com seres naturalmente superiores, civilizados e humanos). Colocando de outra maneira, enquanto raça referese a uma classificação social que diz "este ser não é humano" ou "este ser é menos que humano"; racialização é o processo que desumaniza, que reduz gentes e sociedades colocando-as em situações e relações que os despojam da sua humanidade.

\section{O QUE É LINGUAGEM?}

A teoria da colonialidade do poder de Quijano sugere uma dificuldade para entender as populações colonizadas como agentes comunicativos. Encontrar nos colonizados a

\footnotetext{
${ }^{9}$ Utilizo este tandem ‘colonizado-colonializado' da mesma forma que Patricio Noboa Viñán (2005) utiliza 'colonizador-colonializador', que interpreto referir-se à diferença e relação entre situações de colonialismo no sentido estrito e situações coloniais em tempos em que tais administrações coloniais desapareceram quase por completo do sistema-mundo capitalista, ou seja, situações de colonialidade (p. 95).
}

Revista X, v. 16, n. 1, p. 80-100, 2021. 
habilidade para expressar sentido cosmológico, social, erótico ou econômico complexos não concorda com a sua redução a "quase bestas", "selvagens" ou "primitivos". Em outras palavras, se a ideia de raça, conforme definida na seção anterior, constrói a percepção dos colonizadores, então os colonizados são seres não humanos ou menos que humanos e, portanto, seres sem capacidade para estabelecer uma comunicação dialógica racional, ou seja, sem linguagem.

Podemos afirmar que, no encontro colonial, os colonizadores, ao perceberem as gentes nativas falando, viram naquilo que faziam algo que era menos do que ser capaz de expressar conhecimento. A pergunta é quanto menos. Essa pergunta leva buscar a diferença que existe entre a linguagem como capacidade de expressar conhecimento e a expressividade primitiva e rudimentar; pergunta que, ao mesmo tempo, leva a questionar o paradigma linguístico que estava sendo desenvolvido na Conquista, dentro dos limites políticos da coroa espanhola.

A virada do século marcou uma mudança decisiva no estado da questão linguística na Espanha, já que foi o momento de celebração do castelhano como língua vernácula. Elio Antonio de Nebrija desempenhou um papel fundamental na transformação do castelhano ao escrever a sua gramática. Até então, apenas as línguas clássicas tinham gramáticas. Em sua Gramática da língua castelhana (1492), dedicada à rainha Isabel I de Castela, Nebrija desenvolve, no prólogo, os objetivos do seu trabalho:

O terceiro objetivo deste meu trabalho pode ser aquele que, quando em Salamanca apresentei uma amostra desta obra a vossa majestade real, e me perguntou para que ela seria proveitosa, o reverendo padre Bispo de Ávila me arrebatou a resposta; e, respondendo por mim, disse que depois que a vossa Alteza colocasse debaixo do seu jugo muitos povos bárbaros e nações de línguas peregrinas, e sendo vencidos teriam necessidade de receber as leis que o vencedor impõe ao vencido, e com elas nossa língua, portanto, por meio da minha arte, poderiam vir ao conhecimento dela, como agora nós aprendemos a arte da gramática latina para aprender o latim (NEBRIJA, [1492 2010).

Nebrija era um humanista do Renascimento, formado nos ideais e artes da tradição greco-latina. Dar à língua castelhana um ars grammatica era fazer com que ascendesse do status de língua vulgar - uma vez que as línguas vulgares não precisavam de uma gramática -. Uma gramática é um instrumento para ensinar uma língua. Dar a uma língua uma gramática pressupõe, primeiramente, que essa língua vai ser ensinada e, depois, que é importante aprendê-la. Isso poderia pressupor também que, à diferença das línguas vulgares, essa língua pode expressar conhecimento? As línguas vulgares eram aprendidas 
nas ruas. $\mathrm{O}$ castelhano seria ensinado nas escolas como o latim e o grego. As populações e o território que Nebrija tinha originalmente em mente não estavam do outro lado do Atlântico. Colombo ainda não tinha embarcado. A gramática de Nebrija visa unificar politicamente o reino de Castela, após a vitória final na luta pela Reconquista católica da Península Ibérica que estava sob domínio muçulmano em janeiro de 1492. De qualquer maneira, podemos aventurar-nos a propor que, dez meses mais tarde, os povos do Novo Mundo soaram aos conquistadores espanhóis como falantes de línguas vulgares. Ou seja, devem ter soado como "povos bárbaros" que falavam "línguas peregrinas" as quais se referia Nebrija. Enquanto língua com gramática, o castelhano foi apresentado à rainha como a língua com a qual a Coroa iria implantar ordem ao seu império. O castelhano era então a língua que unificaria o império e que, significativamente, expressaria a sua autoridade, ordem e verdade política.

Certamente, as línguas vulgares, bárbaras e indígenas não podiam expressar a ordem do império espanhol. Dessa forma, pode-se afirmar a "superioridade" do castelhano frente a essas línguas, porque o status da língua é aqui um assunto político. A pergunta que fica pendente é se o castelhano poderia expressar conhecimento, tal como o latim, o grego e o hebraico. Seria necessário ver se existe, em Nebrija, uma relação entre dar uma gramática ao castelhano e alcançar a possibilidade de expressar conhecimento. $\mathrm{O}$ fato de que, até então, somente as línguas com gramáticas eram nas quais se expressava conhecimento (verdadeiro) sustentaria esta possibilidade. Nebrija pensava que, ao dar uma gramática ao castelhano e apresentá-lo como uma língua com "L" maiúsculo, seria uma língua que não só poderia ser usada para o projeto político de unificar o império, mas também com a intenção de expressar mais episteme que doxa? É importante que o projeto político incluísse a expressão da lei e da ordem. Se fosse assim, se para Nebrija aquilo que dava a uma língua o status de ser apta para expressar conhecimento era ter uma gramática, podemos entender, então, a relação entre o conhecimento e o ser comunicador como uma questão racional; o que deve contrastar com a percepção das populações indígenas como carentes de conhecimento, carentes de língua e incapazes de comunicação racional ${ }^{10}$.

É importante levar em conta outro pensador humanista do Renascimento, Bernardo de Aldrete, igualmente a favor da transformação do castelhano em uma língua valorizada.

\footnotetext{
${ }^{10}$ Agradeço aos leitores anônimos da primeira versão deste artigo por me motivarem a esclarecer a diferença e relação entre língua e linguagem. Entendo por linguagem a capacidade de poder estabelecer comunicação por meio de signos, sejam eles orais ou escritos; e por línguas as inúmeras manifestações que a linguagem apresenta nas diversas comunidades que existem em nosso planeta. Como me sugeriram, deixo para outro trabalho (que já está em preparação), traçar as diferenças com outros autores que também discutiram a relação entre linguagem e poder (especialmente Michel Foucault, Pierre Bourdieu e Jacques Derrida).
} 
Em Del origen y principio de la lengua castellana o romance que oi se usa em España ([1606] 1972), a principal tese de Aldrete é que a língua castelhana é filha do latim e que, apesar de ter sido corrompida pelos visigodos, não se alteraram as profundas conexões com o latim clássico, o cristianismo e o conhecimento, que foram logo transferidas ao castelhano (MIGNOLO, 1995, p. 30). Desta forma, do ponto de vista de Aldrete, o castelhano é uma língua de conhecimento porque é filha do latim. Porém, como revela Walter Mignolo (1995), Aldrete também marca uma clara relação entre o castelhano como língua escrita e a questão do civismo (como acontece com o latim).

Porque convém advertir, que os Romanos encontraram Espanha de maneira diferente que os Espanhóis encontraram as Índias, nas quais nenhuma nação estrangeira havia chegado antes, e assim, aquelas gentes carecia de toda sorte de letras, e consequentemente das ciências e estudos delas e da polícia que as acompanham, pois eles viviam como feras nuas (ALDRETE, ([1606] 1972; 1975), Livro 1, capítulo 12).

Mignolo revela a importância da suposição que permite a Aldrete conectar as "feras nuas" à carência das letras. A conexão é o civismo (polícia), que implica primeiro, em ter letras e, logo, maneiras particulares de se vestir. As populações indígenas careciam de ambas. Essa falta não é superficial: carecer de letras e vestimenta era incompatível com a condição de humanidade, e a falta de civismo equivalente à bestialidade. Dada a associação renascentista entre escrita alfabética e civismo, podemos ver até que ponto "a maneira de falar, a maneira de se ver, e a maneira com que os seres humanos devem se comportar" (MIGNOLO, 1995, p. 35) influenciaram a descrição que os colonizadores fizeram sobre a vida social e a conduta pessoal dos colonizados, e até que ponto determinaram a desclassificação dos comunicadores indígenas como seres humanos.

O que se investiga aqui é a relação entre linguagem e humanidade, dado que a negação desta última que constitui a ideia de raça. Procura-se saber quais são as consequências da colonialidade a nível linguístico - como ela condiciona o que é uma linguagem, como a classificação da população mundial em raças que são superiores e inferiores está acompanhada pelo pensamento de que as formas que tem para se expressar também são superiores e inferiores -. As observações sobre os argumentos de Nebrija e Aldrete são o corpo de uma hipótese sobre a relação entre colonialidade e linguagem uma vez que dão conta dessas condições. Nebrija e Aldrete não colocam em prática uma classificação das línguas no sentido aristotélico; antes, dão conta do critério filosófico e linguístico que estava sendo construído no século XVI para estabelecer a superioridade e a inferioridade. Pode-se dizer que este critério inclui: a) ter uma relação filial com as línguas 
tradicionalmente superiores e percebidas como presentes de Deus (o latim, o grego, e o hebraico) e, consequentemente, serem línguas capazes de expressar conhecimento; b) ter a capacidade para o projeto político de unificar um território, incluindo a expressão das leis, a autoridade e a ordem desse território; e c) a conexão entre escrita alfabética e civismo. Portanto, partindo desse critério, quando se avaliam os meios de expressividade de gentes entendidas como "bestas", não são considerados como línguas.

Esse é um ponto chave para entender os aspectos linguísticos da colonialidade, dado que a lógica do critério coloca em prática a racialização ao pressupor uma hierarquia linguística. Dessa forma, as linguagens dos colonizados não são entendidas como diferentes, considerando o que Mignolo (2000) denomina "diferença colonial", entendida como a prescrição da superioridade e inferioridade que transforma diferenças em valores ${ }^{11}$. O que está sendo prescrito no paradigma linguístico renascentista é uma relação entre linguagem e território, linguagem e poder político e jurídico, linguagem e escrita, linguagem e Deus. A linguagem dos colonizadores é $a$ linguagem, o castelhano é uma língua; os meios de expressividade dos colonizados, no entanto, são algo inferior.

Resumindo, os argumentos de Nebrija e Aldrete são importantes para se pensar a racialização linguística porque dão uma ideia do que se pretendia dizer no século XVI: que uma linguagem é ou não é "humana" em um sentido fundamental. As condições que fazem de uma linguagem uma linguagem "real", uma linguagem "no sentido pleno", capaz de comunicação dialógica racional, seguindo os argumentos destes autores, são condições que os meios de expressividade dos colonizados não poderiam satisfazer, precisamente pela colonialidade do poder, ou seja, por serem classificados como gente inferior por natureza.

Dada a ideia de que existe uma conexão entre humanidade, civismo, letras, gramática e conhecimento, assegurada às gentes que têm linguagem - no sentido estrito - pode-se agora perguntar pelas formas linguísticas e comunicativas reduzidas através da transformação racial. Em outras palavras, se os meios de expressividade dos colonizados não eram línguas, o que eram então?

Quero fazer uma distinção entre ser sem-linguagem e ser comunicador simples. Um comunicador simples utiliza e estabelece o que chamo comunicação simples, que vai além da repetição de sons - como fazem os papagaios, por exemplo. Também vai

\footnotetext{
${ }^{11}$ Mignolo, fiel à metodologia do giro decolonial, nunca às definições. Em seus trabalhos, oferece uma variedade de descrições sobre ser e estar, pensar desde e viver na diferença colonial. Uma que acho particularmente clara e sugestiva para o problema que me interessa é a seguinte: "A diferença colonial é o espaço que a epistemologia imperial classificou como o lugar do nãopensar, o lugar dos bárbaros, os inferiores, os primitivos que deveriam aprender a pensar por meio do estudo do grego e do latim e das linguagens modernas imperiais. O espaço fora-da-história, silenciado e desautorizado epistemicamente [...]" (MIGNOLO, 2007, p. 7).
} 
além de praticar aquilo que está inscrito no DNA, como as abelhas ou as formigas, que realizam tarefas coletivas complexas que dependem apenas de códigos inscritos, sem consciência ou reflexão. A comunicação simples revela um grau de consciência, e, inclusive, de autoconsciência. Os comunicadores simples emitem sons e fazem gestos que têm um sentido que, embora não seja meramente denotativo, nada mais é do que uma comunicação dialógica racional. Ao apresentar estes termos, comunicação simples e comunicador simples, o que procuro é nomear e capturar a ficção colonial. Ou seja, não há linguagens de comunicação simples nem comunicadores simples. Não há características que façam das populações colonizadas comunicadores simples ou, de suas linguagens, linguagens de comunicação simples. O que existem são características que o colonizador pensa que as gentes têm e que as tornam comunicativamente inferiores, negando assim o status de linguagens "no sentido pleno" às suas capacidades de expressividade.

Como expliquei, a relação modernidade/colonialidade é uma estrutura de poder que afeta a lógica da percepção. Meu trabalho se pergunta precisamente isso: como se chega a conceber - linguística e expressivamente - aos colonizados-colonializados como seres inferiores por natureza, e a suas formas de expressividade como formas rudimentares e inferiores? Essas perguntas procuram ver e ouvir aos colonizados-colonializados com os olhos e ouvidos do colonizador-colonializador e, ao mesmo tempo, ver na formação de uma percepção dos colonizadores-colonializadores de si mesmos como seres humanos plenos. Portanto, de alguma maneira, as perguntas colocam em prática e exercitam a colonialidade. As perguntas surgem ao considerar a intersubjetividade da sociedade colonial de uma posição "meta” que aborda a dominação colonial linguística.

\section{O QUE É COLONIALIDADE DA LINGUAGEM?}

A colonialidade da linguagem é o termo que estou propondo para nomear um processo que acompanha a colonialidade do poder. É um aspecto do processo de desumanização das populações colonizadas-colonializadas através da racialização. $\mathrm{O}$ problema que a colonialidade da linguagem propõe é a relação entre raça/linguagem. Uma vez que a racialização é inseparável da apropriação e redução eurocêntricas do universo das populações colonizadas ${ }^{12}$, a relação raça/linguagem é praticada dentro de uma filosofia, ideologia e política eurocêntricas que incluem uma política linguística.

\footnotetext{
${ }^{12}$ Por universo entendo a realidade das populações colonizadas-colonializadas e suas construções de realidade, a formação material e discursiva de si mesmos, de suas relações sociais, de seu entendimento de mundo e das maneiras de habitar nele, de suas relações com o "meio-ambiente", etc.
}

Revista X, v. 16, n. 1, p. 80-100, 2021. 
Desde seu interior, o imenso aparato epistêmico-ideológico da modernidade permite que a imaginação colonial pressuponha os colonizados-colonializados como seres menosque-humanos, expressiva e linguisticamente.

A ideia eurocêntrica da linguagem conecta a língua, a gramática, a civilização e a escrita alfabética ao conhecimento, e naturaliza essas características e atributos como linguagem "em sentido pleno". É indiscutível, dentro do paradigma moderno/ colonial, o fato de que os colonizadores-colonializadores têm linguagem, assim como, o de que os colonizados-colonializados carecem dela. Apresentei o termo comunicação simples para capturar a imaginação colonial dos colonizados-colonializados como seres que não têm linguagem real, ou seja, que não têm expressividade valorizada do ponto de vista eurocêntrico.

Assim, para revelar como a colonialidade da linguagem opera - entendida como uma das facetas do processo da desumanização das populações colonizadas - torna-se necessária uma mudança paradigmática, pois o conceito de linguagem que as instituições do Renascimento e do Iluminismo supõem torna impossível perceber o colonizadocolonializado como um ser que possui linguagem "em sentido pleno", ou pensar que seja outra coisa além de um comunicador simples. Essa mudança de paradigma permitiria revelar e explorar as relações linguísticas de poder. Porém, a mudança paradigmática não pode ser apenas relativa, não se pode simplesmente ignorar a colonialidade. É somente fora da filosofia, da ideologia e da política linguística moderno/coloniais que a racialização pode ser entendida e revelada como um processo de redução, invisibilização e eliminação dos mundos de sentido dos seres colonizados-colonializados. Aquilo que está fora da colonialidade não pode ser simplesmente pressuposto. Se fosse possível, minha hipótese não faria sentido. Para dar essa mudança paradigmática que permita entender a comunicação de uma maneira diferente da realidade comunicativa vista e estabelecida segundo a lógica da modernidade/colonialidade e da diferença colonial entre expressividade superior e inferior por natureza, me apoiarei na noção de linguajar que utiliza o biólogo e pensador chileno Humberto Maturana (1990; 1999).

A noção de linguajar abre uma opção para pensar a linguagem não como um produto acabado, mas como uma atividade progressiva e localizada. Interessa-me a passagem do substantivo ("linguagem") ao verbo ("linguajar") para contrapor a lógica de sentido da modernidade/colonialidade. O substantivo linguagem é uma coisa dada, que precede à interação e pressupõe uma comunidade - algo que é comum -. No caso das línguas coloniais, como o espanhol e o inglês, essa comunidade abrange uma gente cuja linguagem é. A linguagem como coisa institucionalizada, ordenada com uma gramática, como língua 
de um império ou nação, fecha-se a qualquer interação que tente complicar a variedade e heterogeneidade de usuários e situações de interação. O verbo linguajar, pelo contrário, tem a mudança e a continuidade como características fundamentais. $\mathrm{O}$ sentido aqui não é dado e, além disso, o vínculo entre sentido e linguajar possui a mesma complexidade que as interações entre os usuários, incluindo a complexidade relacionada ao poder e às situações de dominação. O sentido é criado nessas interações; em vez de estar frente a uma coisa produzida, com características definidas por aqueles que têm poder e que vinculam tal poder ao conhecimento, a ideia de linguajar permite ver a representação - no sentido artístico do termo - da expressividade e da comunicação. Essas interações não permitem que a linguagem se encerre em si mesma. Não há um linguajar abstrato. Como práxis, é sempre produzido por alguém em determinado tempo e espaço. Em outras palavras, o exercício de linguajar sempre está relacionado à materialidade da vida cotidiana, o que facilita uma forma de entender as práticas e experiências dos interlocutores.

Mesmo que essa passagem de substantivo/coisa a verbo/ação não seja original de Maturana e esteja presente em outros autores, como, por exemplo, José Ortega y Gasset e sua "nova filologia"13, recorro a Maturana porque a sua ideia de linguajar permite revelar a relação entre a linguagem como ação e maneiras de viver outras.

É através do linguajar como atividade em comunidade - linguajar juntos - que as gentes criam suas realidades. Essa relação abre espaço para uma compreensão sobre comunidades linguísticas, sobre gente existindo através do exercício do linguajar e convivendo de maneiras particulares, sobre espaços de coexistência (re)criados e movidos coletivamente. Além disso, considerando que as maneiras de ser e estar juntos em um coletivo, de entender e dar sentido ao mundo coletivamente, de organizar coletivamente o social em todos os seus níveis de existência (cognitivo, espiritual, econômico, reprodutivo, jurídico, pedagógico, afetivo, etc.), e considerando que tudo o que uma comunidade é, se dá nesse exercício de linguajar, é essa prática a que permite entrar nos mundos de sentido não eurocêntricos, por mais que os relatos da modernidade tenham invisibilizado tudo isso. Desta forma, o linguajar mostra, à maneira do giro decolonial - vale esclarecer, sem querer incluir a Maturana nesse grupo -, uma exterioridade que não era possível dentro do paradigma moderno/colonial.

\footnotetext{
${ }^{13}$ Em sua "nova linguística" (década do cinquenta), Ortega já sugere uma passagem de substantivo a verbo para alcançar uma aproximação mais precisa à realidade da linguagem. Para Ortega, a abstração "linguagem" é só uma primeira aproximação, porque realmente isso que os linguistas chamam "linguagem" não existe na realidade, é apenas uma imagem utópica e artificial. No entanto, Ortega propõe que a linguagem nunca é um fato acabado ou uma coisa terminada, ao contrário, sempre está in statu nascendi (BECKER, 1991, p. 228).
} 
O que o marco maturaneano permite, é revisar aquilo que a modernidade/ colonialidade prescreve como seres não humanos, e que, portanto e por definição, não possuem uma linguagem que possa ser considerada "real", e ver esses seres de fora da matriz colonial de poder e suas restrições conceituais e linguísticas: vê-los como gente que linguajeia.

Dessa forma, a mudança de paradigma que a ideia de linguajar habilita, permite argumentar que a colonialidade da linguagem produz, na situação colonial, uma disposição da parte dos colonizadores-colonializadores de se comunicarem entre si enquanto reduzem possíveis interlocutores a comunicadores simples e suas linguagens a ferramentas rudimentares de expressividade. Aqui pode se ver a materialidade da afirmação que fiz na introdução, segundo a qual o diálogo foi colonizado. Segundo Mikhail Bakthin ([1979] 2002), a condição sine qua non do diálogo é que o falante pressuponha em sua enunciação "uma compreensão ativa repleta de resposta" (p. 258). Esse papel ativo do outro no processo de comunicação discursiva real (p. 259) é precisamente o que a colonialidade rejeita ao negar aos colonizados-colonializados a capacidade e agência comunicativa dos colonizadores-colonializadores. O ponto crucial é que agora se pode analisar a colonialidade da linguagem como uma produção e não como algo dado.

Para completar a mudança paradigmática, sugiro a ideia de monolinguajar para designar as práticas materiais e discursivas de racialização linguística desde a perspectiva da linguagem. Com esta ideia quero significar algo que difere do monolinguismo. Como descrevi anteriormente, a classificação das gentes em raças superiores e inferiores foi acompanhada da compreensão de suas ferramentas expressivas em termos de superioridade e inferioridade. Também descrevi o critério que os humanistas renascentistas começaram a construir para embasar essa superioridade-inferioridade, no qual somente os colonizadores possuíam linguagem "em sentido pleno" - daí seu monolinguismo -. Contudo, o monolinguajar me permite questionar a interação comunicativa entre aqueles que percebem a si mesmos como seres que têm linguagem "em sentido pleno", e os outros seres como bestas, quase animais, e que, portanto, são considerados como seres que carecem de linguagem, mas que podem ser treinados para entender os colonizadorescolonializadores suficientemente bem para obedecer ordens e fazer o que eles querem. Em síntese, embora seja possível argumentar que e como a colonialidade anula a possibilidade de diálogo e criação dialógica com significado entre colonizadores e colonizados, isso não significa que não houve comunicação alguma entre eles. É essa prática comunicativa que vou caracterizar como monolinguajar. 
Quero dar um exemplo de uma manifestação do que entendo por monolinguajar. Talvez seja a primeira, já que aparece na entrada da quinta-feira, 11 de outubro de 1492, do diário de viagem de Cristóvão Colombo, no qual o Almirante narra seu encontro com os nativos da ilha Guhanahaní:

Como tinham muita amizade conosco, e porque conheci que era gente que melhor seria livre e se converteria à nossa santa fé com amor e não por força, dei para alguns deles uns bonés vermelhos e uns colares de vidro que colocavam no pescoço, e muitas outras coisas de pouco valor, com as quais tiveram muito prazer e ficaram como que nossos, e isso era maravilhoso. Os quais depois vinham nadando às barcas dos navios onde nós estávamos [...] e trocavam muitas coisas conosco por outras que nós lhes dávamos, como cordões com vidros e guizos. Enfim, tudo tomavam e davam daquilo que tinham com boa vontade, mas me pareceu que aquela gente era muito carente de tudo. Eles, e também as mulheres andam todos nus como a sua mãe os pariu. E todos os que eu vi eram mancebos, de modo que nenhum tinha mais de trinta anos de idade. Muito bem feitos, de muitos formosos corpos e caras muitas boas, os cabelos grossos quase como sedas de rabo de cavalo, e curtos [...], eles são da cor dos canários, nem negros nem brancos [...] Eles não trazem armas nem as conhecem, porque mostrei-lhes espadas e as tomavam pelo fio e se cortavam por conta da ignorância. Não têm nenhum ferro, suas azagaias são umas varas sem ferro e algumas delas têm no cabo um dente de peixe e outras coisas. No geral, eles são todos, de boa estatura e de bons modos, bem feitos. Eu vi que alguns tinham marcas de feridas em seus corpos e fiz-lhes sinais do que era aquilo e eles me mostraram que como gente de outras ilhas chegavam lá e os queriam tomar e eles se defendiam. E eu pensei, acho que eles vêm do continente para tomá-los por cativos. Eles devem ser bons servidores e de bom engenho, pois vejo que com muita atenção dizem tudo o que eu os dizia. E creio que rapidamente se fariam cristãos, ao que me pareceu que não tinham nenhuma crença. Eu, como agradecimento à Nosso Senhor, levarei às Vossas Altezas eis daqui, ao tempo de minha partida, para que aprendam a falar (COLOMBO, s. f., p. 398-399).

O paradigma linguístico moderno/colonial informa a impressão que Colombo teve. Por um lado, ele nega o status da linguagem a aquilo que os nus, ignorantes, pobres, ingênuos, sem religião e dóceis nativos falavam, ao anunciar que vão levar seis deles à Espanha para que aprendam a falar. Por outro, celebra a habilidade que os nativos têm de entender e responder com sinais e repetir tudo o que ele disse como algo de grande valor - tal como seus corpos bem formados - quando considera sua escravidão. Desta forma, sugiro que a interação entre Colombo e a população de Guhanahaní naturaliza a 
dominação colonial, discursiva e dialogicamente. Ele não vê nem se comunica com eles como interlocutores, mas sim como escravos.

$\mathrm{Na}$ interação entre amo e escravo não há uma comunidade linguística propriamente dita - no sentido moderno, habermasiano, por exemplo -, mas existe, uma forma de socialização entre eles. Isso é o que eu quero ilustrar com a ideia de monolinguajar; uma socialização que cria uma forma de vida desumanizante para as pessoas colonizadas que são seus destinatários. A escravidão e a encomenda não são somente modos de produção; são formas de vida acompanhadas de leis, deslocamento e deportação de gente em plantações, minas e missões, e de instituições como a mita. Há uma comunidade no sentido de um agregado de gente que vive e se mantém junta para uma função em particular; porém a única coisa que importa é a vontade do colonizador-colonializador, o que o amo quer com e desses seres e corpos que são sua propriedade.

$\mathrm{O}$ destinatário no ato de monolinguajar é aquele que entende o que o amo quer e sabe como fazê-lo, porém, as suas formas de vida comunais, seus saberes coletivos, sua criatividade e, seu linguajar, não são importantes. O monolinguajeio desumaniza, porque silencia o linguajeio comunitário ${ }^{14}$. Nesse sentido, monolinguajar marca uma diferença fundamental - especialmente para a ideia de ação comunicativa - entre comunicação hostil - que, mesmo assim, cria um sentido de reconhecimento e comunicação incomunicativa, ou seja, comunicação que assume que o outro é, por natureza, incapaz de expressividade racional.

Dada a impossibilidade de ver o colonizado como um interlocutor - que é o mesmo que vê-lo como um comunicador simples -, não há uma disposição comunicativa por parte do colonizador-colonializador, surdo a toda possibilidade de sentido que saia da boca do colonizado-colonializado. Nesse caso, dificilmente pode se falar sobre um "viver juntos"

\footnotetext{
${ }^{14}$ Dizer que o linguajar comunitário é silenciado não deve ser entendido como não existente. Igualmente, dizer que a modernidade/colonialidade ignorou, deslocou e subalternizou perspectivas epistêmicas e experiências de vida outras não quer dizer que elas não existam. A colonialidade da linguagem faz parte do processo que busca negar aos colonizados-colonializados como gente. Porém, é certo que para conseguir isso, teria que acontecer muito mais coisas. Teriam que perder a capacidade de continuar vivendo coletivamente e linguajeando. Enquanto os colonizados-colonializados continuem linguajeando, continuam poderosamente relembrandose, representando e praticando maneiras de viver contra a redução que as missões trouxeram, a dispersão que a escravidão criou e a universalidade da modernidade e suas instituições. Ainda que tenham internalizado algumas palavras do domínio das linguagens coloniais, ainda que tenham perdido conceitos de suas cosmologias, os que habitam a diferença colonial, e aos quais se negou possuir uma linguagem em sentido pleno, falam de formas que rejeitam a ideia de linguagem segundo enunciada e imposta pela modernidade.
} 
ou "viver em companhia de outros" - que é o que realmente significa "conversar"15 -. Porém, se houvesse um "ir juntos" no monolinguajar, seria tal que só o colonizador-colonializador teria agência e mobilidade, e ele não seguiria apenas a direção que quisesse, mas sim uma que também excluísse toda possível direção que o colonizado-colonializado quisesse dar. Dessa forma, e com a ideia de monolinguajar em mente, a mudança paradigmática revela a diferença entre comunicação dialógica racional e comunicação simples como uma relação de dominação sustentada por práticas e instituições de monolinguajeio orientadas para a racialização/desumanização do colonizado-colonializado como sujeito comunicativo/enunciador, interlocutor - e, consequentemente, apresentar a colonialidade da linguagem como um processo de dominação.

\section{CONCLUSÃO}

Este artigo oferece uma reflexão desde o giro decolonial sobre a relação entre raça, linguagem e fala. A colonialidade como relação comunicativa não é algo que possa ser explicado seguindo a teoria da ação comunicativa moderna. Pelo contrário, a teoria moderna da comunicação esconde e disfarça a lógica do silêncio da colonialidade linguística. Por isso, propus essa mudança de paradigma que mostra o mundo (de sentido) moderno/colonial como um sistema de poder exercido sobre a construção da realidade. Esta mudança abre as portas para a pesquisa da produção histórica da colonialidade linguística, que se pergunta sobre as maneiras que as atividades e esforços comunicativos foram se transformando à medida que as gentes foram racializadas através de instituições jurídicas, políticas, educativas, trabalhistas e civis. E também abre as portas para uma análise em código decolonial de como essas transformações foram rejeitadas e contestadas de muitas maneiras e a partir de diversas lógicas. Porém, vale salientar, que o exercício de revelar o lado colonial, trazendo à luz aquilo que a modernidade manteve fora do espaço público, é um primeiro passo já decolonial nessa direção.

Dadas as condições comunicativas criadas pela colonialidade linguística, não podemos assumir que os que estamos na diferença colonial podemos ver-nos e entendernos mutuamente e entrar na conversação crítica como se não existisse colonialidade. Isso é fundamental na hora de pensar e buscar conexões entre alternativas decoloniais, entendendo-as como práticas e projetos mais ou menos articulados que resistem à colonialidade do poder em suas múltiplas e interconectadas formas. Uma teoria decolonial

\footnotetext{
${ }^{15}$ Dicionário da Real Academia Espanhola. 
da comunicação deve enfrentar e negociar as complicações da dificuldade de diálogo que a colonialidade da linguagem produziu.

\section{REFERÊNCIAS}

ALDRETE, B. J. ([1606] 1972). Del origen y principio de la lengua castellana o romance que oi se usa en España. GIMÉNEZ, L. Nieto (Org.). Madrid: Consejo Superior de Investigaciones Científicas, 1972.

BAJTÍN, M. M. ([1979] 2002). El problema de los géneros discursivos. En Estética de la creación verbal (pp. 248-293). Buenos Aires: Século XXI editores.

BECKER, A. A short essay on language. In: STEINER, F. (Org.). Research and Reflexivity. Londres: Sage, 1991. p. 226-234.

CASTRO-GÓMEZ, S. (Org.) La reestructuracion de las ciencias sociales en América Latina. Bogotá: Pensar, Instituto de Estudios Sociales y Culturales: Pontificia Universidad Javeriana, 2000.

CASTRO-GÓMEZ,S.;MENDIETA,E.(Orgs.).Teoriasindisciplina:Latinoamericanismo, postcolonialidad y globalización en debate. México DF: Miguel Ángel Porrúa, 1998.

COLÓN, C. Diarios de Colón. Disponível em: <https://juancarloslemusstave.files. wordpress.com/2014/07/diarios-de-colc3b3n.pdf>. Acesso em: 28 ago. 2020.

DUSSEL, E. 1492: El encubrimiento del Otro. Hacia el origen del "miro de la Modernidad". Bogotá: Editorial Nueva América, 1992.

ESCOBAR, A. Worlds and Knowledges Otherwise. The Latin American modernity/ coloniality Research Program: CEDLA, v. 16, p. 31-75. 2004.

FREIRE, P. Pedagogia do Oprimido. 25ª ed. Rio de Janeiro: Paz e Terra, 1998.

GROSFÓGUEL, R. A Decolonial Approach to Political-Economy: Transmodernity, Border Thinking and Global Coloniality. Kult 6 - Special Issue Epistemologies of Transformation: The Latin American Decolonial Option and its Ramifications, p. 10-38. 2009.

ISASI-DÍAZ, A. M.; MENDIERA, E. (Orgs.). Decolonizing epistemologies. Latina/o theology and philosophy. Nova Iorque: Fordham University Press, 2011. p. 68-86.

MALDONADO-TORRES, N. Post-continental Philosophy and the Decolonial Turn. 
Manuscrito, 2005.

MATURANA, H. R. Emociones y lenguaje en educación y política. Santiago de Chile: Centro de Estudios de Desarrollo, 1990.

MATURANA, H. R. Transformación en la convivencia. Santiago de Chile: Dolmen Ediciones, 1999.

MIGNOLO, W. The Darker Side of the Renaissance. Literacy, Territoriality and Colonization. Michigan: The University of Michigan Press, 1995.

MIGNOLO, W. Local Histories/Global Designs. Coloniality, Subaltern Knowledges and Border Thinking. Nova Jersey: Princeton University Press, 2000.

MIGNOLO, W. La idea de América Latina. La herida colonial y la opción decolonial. Barcelona: Gedisa, 2007.

NEBRIJA, E. A. ([1492] 2010) Gramática de la lengua castellana. In: ROMEO, Galindo; MUÑOZ, L. Ortiz. (Orgs.). Madrid: Edición de la Junta del Centenario, 2010. Disponível em: http://www.ciudadseva.com/textos/otros/gramati.htm. Acesso em: 28 ago. 2020.

NOBOA, P. La matriz colonial, los movimientos sociales y los silencios de la modernidad. In: WALSH, C. (Org.). Pensamiento crítico y matriz (de)colonial. Quito: Abya-Yala, 2005. p. 71-109.

QUIJANO, A. Colonialidad y modernidad/racionalidad. In: BONILLA, H. (Org.). Los conquistados. 1492 y la población indígena de las Américas. Ecuador, LibriMundi, Tercer Mundo Editores, 1989. p. 437-448.

QUIJANO, A. Colonialidad del poder, eurocentrismo y América Latina. In: CLIMACO, D. Assis. (Org). Cuestiones y Horizontes. Antología esencial de la Dependencia HistóricoEstructural a la Colonialidad/Descolonialidad del Poder. Buenos Aires: CLACSO, 2014. p. 777-832.

QUIJANO, A. Colonialidad del poder y clasificación social. In: CLIMACO, D. Assis. (Org.). Cuestiones y Horizontes. Antología esencial de la Dependencia HistóricoEstructural a la Colonialidad/Descolonialidad del Poder. Buenos Aires: CLACSO, 2007. p. 285-327.

WALLERSTEIN, I. The Modern World System I: Capitalist Agriculture and the Origins of the European World-Economy in the Sixteenth Centry. Nova Iorque: Academic Press, 1974. 
WALSH, C. Interculturalidad, Estado, Sociedad. Luchas (de)coloniales de nuestra época. Quito: Universidad Andina Simón Bolívar/Abya Yala, 2009.

WALSH, C.; SCHIWY, F.; CASTRO-GÓMEZ, S. (Orgs.). Indisciplinar las ciencias sociales. Geopolíticas del conocimiento y colonialidad del poder. Perspectivas desde lo Andino. Quito: UASB/Abya Yala, 2002. 